\title{
Valoración del aprovechamiento de las ventajas de la alianza del pacífico por parte de las Pymes del Noroeste de México
}

\author{
Volumen XIX No (1). Enero-Junio 2019. Pág. 25-48
}

ISSN: 0121-1048 IMPRESO ISSN: 2422-3220 EN LÍNEA

\section{Becerra-Pérez, Luis A:}

Universidad Autónoma de Sinaloa, Facultad de Ciencias Económicas y Sociales,

Blvd. Universitarios y Av. de las Américas, Módulo III, C.U., C.P. 80010, Culiacán, Sinaloa México.

becerra@uas.edu.mx

autor correspondiente

\section{Sánchez-Meléndez, Eduardo P.}

Universidad Autónoma de Sinaloa, Facultad de Contaduría y Administración, Blvd. Universitarios y Av. de las Américas, Módulo IV, C.U., C.P. 80010, Culiacán, Sinaloa México.

lci.pabelsanchez@hotmail.com

\begin{abstract}
Resumen
Existen ventajas para las empresas y los ciudadanos en los tratados comerciales signados entre países. Dependiendo del grado de internacionalización de las empresas y del esfuerzo de promoción de los gobiernos, esas ventajas pueden ser más o menos aprovechadas. Este artículo analiza el proceso de internacionalización de una empresa, que en el marco de la Alianza del Pacífico (AP) inició exportaciones hacia los países firmantes del acuerdo, y presenta los resultados de una encuesta aplicada en el noroeste de México. La evidencia encontrada muestra que el proceso de internacionalización de las Pymes es gradual, creciente, requiere recursos, apoyos, conocimiento, y consiste en etapas, para lo cual la empresa necesita identificar sus ventajas competitivas y su capacidad para internalizarlas. Además, el documento valida la existencia de un bajo aprovechamiento de las ventajas contempladas por la AP por parte de las empresas exportadoras de la región, dado su conocimiento limitado del acuerdo y la falta de promoción del gobierno .
\end{abstract}

Palabras clave: Alianza del Pacífico, Tratado de libre comercio, Internacionalización de Pymes.

Códigos JEL: F13, F14, F15

\footnotetext{
- Citar: Becerra Pérez, Luis A. y Sánchez Meléndez, Eduardo P. (2019). Valoración del Aprovechamiento de las Ventajas de la Alianza
} del Pacífico por parte de las Pymes del Noroeste de México. Inquietud Empresarial, XIX (1), 25-48. 


\title{
Valuation on the use of the advantages of the pacific alliance by SMEs in Northwestern Mexico
}

\begin{abstract}
There are advantages for companies and citizens in trade agreements signed between countries. Depending on the degree of internationalization of companies and the efforts of government promotion, these advantages can be more or less exploited. In this way, this article analyzes the process of internationalization of a company, which in the framework of the Pacific Alliance (PA) trade agreement began exports to the signatory countries of the deal and presents the results of a survey applied in northwestern Mexico. The evidence found shows that the process of internationalization of the company (SMEs) is gradual, growing up requires resources, support, knowledge, and consists of stages, for which the company needs to identify its competitive advantages and its ability to internalize them. Besides, it validates the existence of low usage of the benefits contemplated by the PA by the exporting companies in the region, given their limited knowledge of the agreement and the lack of government promotion.
\end{abstract}

Keywords: Pacific Alliance, Free Trade Agreement, Internationalization of SMEs

JEL Codes: F13, F14, F15

\section{INTRODUCCIÓN}

Con el eslogan de "America First" (Primero América) Donald Trump manifestó su idea de poner primero los intereses y valores de Estados Unidos antes de cualquier otro esfuerzo grupal en favor del desarrollo global. O sea, en política internacional favorece el unilateralismo en lugar del multilateralismo. Con esta filosofía, en cada organismo internacional deben privar primero los intereses de Estados Unidos y cada negociación y tratado comercial es independiente. En el caso nuestro, obligó a México y Canadá a iniciar un proceso de renegociación del Tratado de Libre Comercio de América del Norte (TLCAN), amenazando con la posibilidad de salirse del acuerdo en caso de no cumplir sus expectativas. Además, presionó a México para que aprobara una reforma laboral mucho más ad hoc a las nuevas condiciones internacionales de comercio incorporadas al nuevo tratado negociado, aun así, no aprobado hasta la fecha (junio de 2019).

Estados Unidos se retiró del Acuerdo Transpacífico de Cooperación Económica (TPP, por sus siglas en inglés), del Acuerdo Climático de París, del Consejo de Derechos Humanos de la Organización de las Naciones Unidas (ONU), de la Organización de las Naciones Unidas para la Educación, la Ciencia y la Cultura (UNESCO), entre otros.

Unilateralmente la administración del presidente Donald Trump ha emprendido acciones arancelarias proteccionistas sobre el acero y el aluminio; ruta similar se proyecta para la industria automotriz, amén de otras industrias a las cuales también presiona para que reubiquen y/o cambien sus decisiones de inversión con la idea que generen empleos al interior de Estados Unidos. 
Sus acciones también han dado pie a una guerra comercial con China y otros países a través de la implementación de políticas arancelarias específicas a sectores y/o productos, incluso en el caso de México, imponer aranceles generales para todas sus exportaciones hacia Estados Unidos bajo un mecanismo creciente hasta llegar al 25\%, situación de gran impacto en los flujos comerciales entre ambas naciones. Por razones obvias, esto traería una reconfiguración del comercio, inicialmente bilateral, y posteriormente regional.

Actualmente, en el mundo se tienen nuevas visiones en el ámbito del comercial internacional, las cuales contradicen al espíritu de apertura y globalización que se ha vivido en los últimos 40 años. Pareciera que estamos pasando de la "aldea global" de McLuhan a la aldea local de Trump.

Economías, otrora defensoras de la apertura y el libre comercio, exhiben ahora tendencias proteccionistas y restricciones para que la inversión extranjera directa se mueva libremente; mientras economías tradicionalmente cerradas y con modelos diferentes al libre mercado, están paulatinamente emigrando a sistemas de comercio mixto y son tolerantes a la inversión extranjera. Ejemplos de lo primero es Estados Unidos, en tanto de lo segundo es Rusia y, recientemente, Cuba.

Ante ese escenario, los acuerdos comerciales y organismos internacionales de fomento al libre comercio, el desarrollo sustentable, el medio ambiente, la paz y los derechos humanos tienen una importancia estratégica, ya sea en un sentido $u$ otro.

Según la Comisión Económica para América Latina y el Caribe (CEPAL), de continuar esta tendencia en las restricciones comerciales, las barreras a las importaciones mundiales podrían representar un trillón de dólares, equivalente al $6 \%$ del comercio global de bienes en el 2018. Existe también, señala, una erosión del apoyo al sistema multilateral de comercio y un movimiento hacia relaciones comerciales basadas en el poder (Bárcenas, 2018).

Dado este nuevo contexto internacional, México debe replantear su política comercial hacia el exterior con una visión de diversificación e integración a otras regiones que también son comercialmente importantes.

México cuenta con un amplio stock de instrumentos de promoción y asociación que apoyan el desarrollo de su comercio exterior. La mayoría de ellos, forman parte de la estrategia económica de apertura comercial iniciada desde la década de 1980.

A la fecha, el país cuenta con 12 tratados de libre comercio con 46 países, 32 acuerdos para la promoción y protección recíproca de las inversiones con 33 países y 9 acuerdos de alcance limitado en el marco de la Asociación Latinoamericana de Integración (ALADI).

Entre los tratados y acuerdos comerciales vigentes existe uno denominado Alianza del Pacífico (AP), el cual fue signado en el 2011 por los gobiernos de Colombia, Chile, Perú y México, y entró en funciones en el 2012. Además de los acuerdos arancelarios, este tratado incluye asuntos de propiedad industrial, flujos de capital y facilidades para la circulación de personas entre los cuatro países.

Su cumbre 13, llevada a cabo en México en julio de 2018, demostró el potencial de este acuerdo comercial. Según la presidencia de México (Peña, 2018) la AP concentra el 36\% 
del Producto Interno Bruto (PIB) de América y el Caribe, $57 \%$ de su comercio y el $38 \%$ de la captación de inversión extranjera directa. Se debe destacar que en esta cumbre participaron Australia, Canadá, Nueva Zelanda y Singapur con la intención de sumarse a las negociaciones como Estados Asociados, lo que por supuesto fortalece el acuerdo comercial. Además, asistieron representantes de los países del Mercosur (Argentina, Brasil, Paraguay y Uruguay) con el objetivo de promover un mayor acercamiento entre ambos bloques.

Según datos ventilados en dicha cumbre, el $96 \%$ de los bienes y servicios que hoy se intercambian entre Perú, Chile, Colombia y México lo hacen libre de arancel, además de beneficiarse de las facilidades y apoyos pactados en los distintos programas incluidos en el acuerdo. Por ejemplo, existe un fondo de capital emprendedor, un fondo de infraestructura, un programa de movilidad de personas (eliminación de visa de turista), un programa de participación de jóvenes en proyectos de trabajo y sociales, un programa de movilidad académica y estudiantil (becas), entre otros.

Los objetivos de la AP son: a) construir, de manera participativa y consensuada, un área de integración para avanzar progresivamente hacia la libre circulación de bienes, servicios, capitales, personas y economía; b) impulsar un mayor crecimiento, desarrollo económico y competitividad de las economías de sus integrantes, con miras a lograr mayor bienestar, superar la desigualdad socioeconómica e impulsar la inclusión social de sus habitantes; c) convertirse en una plataforma de articulación política, integración económica y comercial, y proyección al mundo, con énfasis en la región Asia-Pacífico.
La estructura ejecutiva de AP es una presidencia anual (rotativa), un consejo de ministros, un grupo de alto nivel y un grupo de países observadores. Se reúnen en cumbres para revisar los avances y determinar mejoras. La estructura operativa de la AP es una coordinación general y agencias especializadas de los 4 países. El consejo de ministros está integrado por los ministros de comercio y de relaciones exteriores de los países miembros, sus atribuciones consisten en tomar decisiones encaminadas al cumplimiento de los objetivos previstos en el acuerdo marco, así como también en las declaraciones presidenciales de la AP. El grupo de alto nivel está compuesto por los viceministros de comercio y de relaciones exteriores. Este grupo se encarga de supervisar los avances de los grupos técnicos y preparar propuestas para el acercamiento externo con otros organismos o grupos. Los países observadores no son miembros, sin embargo, pueden participar y sumarse en calidad de Estados Asociados, beneficiándose del acuerdo y de las disposiciones establecidas por el consejo de ministros (AP, 2011).

A pesar del amplio abanico de acuerdos comerciales que tiene signados México, dada la existencia de problemas estructurales y restricciones técnicas, legales, ambientales y hasta culturales, muchas empresas no aprovechan las ventajas que dichos instrumentos proveen, especialmente las Pequeñas y Medianas Empresas (PYMES).

Una explicación sobre el bajo aprovechamiento de los tratados comerciales, exceptuando al TLCAN, es el poco conocimiento sobre las oportunidades que ofrecen los mismos. En un entorno donde la mayoría de las empresas no tiene perfecta información, registran un déficit de recurso humano capacitado en procesos de comercio 
exterior, problemas de productividad, calidad e inexistencia de economías de escala, es muy complicado pensar que puedan aprovechar las ventajas incluidas en los acuerdos comerciales internacionales.

La desinformación inhibe a las empresas de poder incursionar en los mercados internacionales. Además, en muchos casos persiste el miedo natural al cambio y una visión limitada de lo que es la internacionalización.

Según Castellanos (2017), los productores locales pueden tener acceso a mercados más grandes que el nacional, obtener precios más competitivos, conseguir mejores proveedores, intercambiar productos y hasta conocimientos, y aprovechar las ventajas de esos mercados. Desafortunadamente, cuando se habla de comercio internacional solo se piensa en el país vecino del norte, ya ni siquiera en Canadá, que también es parte del TLCAN (Gómez, 2013).

Es muy importante fomentar una cultura de comercio exterior en las empresas, eliminar el miedo natural a incursionar en otros mercados que no sea el estadounidense y así promover las exportaciones hacia Sudamérica, Europa, África, y Asia.

El comercio exterior de México está muy concentrado hacia Estados Unidos. Se requiere ver oportunidades en otros mercados y aprovechar los tratados comerciales con los que cuenta México, sin dejar de lado a los países latinoamericanos por considerarlos menos desarrollados (Castellanos, 2017). Existen grandes oportunidades en esta región con un

un alto potencial para productos provenientes de México, específicamente Sinaloa. Tanto empresas como gobiernos deben trabajar en conjunto para poder detectar grandes oportunidades en los mercados externos de esos países (De La Mora, 2017).

El objetivo general de este trabajo fue analizar el aprovechamiento la AP por parte de las empresas exportadoras del Estado de Sinaloa en los primeros seis años de operación (2012-2017). Para ello, se realizaron dos cosas: a) un estudio de caso en una empresa exportadora hacia los países miembros de la AP; y b) se aplicó una encuesta general al sector exportador de Sinaloa para conocer su percepción y conocimiento de las oportunidades que incluye dicho tratado comercial.

La hipótesis para comprobar fue que a seis años de iniciada la AP existe un desaprovechamiento por parte de las empresas, sobre todo PYMES, de las ventajas comerciales que ofrece este acuerdo, evidenciando la falta de una estrategia de internacionalización de las empresas de Sinaloa y una escasa promoción de dichas ventajas por parte de las autoridades federales y locales responsables de hacerlo.

El artículo se divide en cinco partes. La primera, es la presente introducción, en la cual se justifica la investigación y se plantea la hipótesis; la segunda, explica el marco teórico; la tercera, detalla la metodología aplicada; la cuarta parte, da cuenta de los resultados; y la quinta, presenta una breve conclusión de la investigación.

\section{MARCO TEÓRICO}

\subsection{La internacionalización de la empresa}

Este apartado se inicia con un resumen de las distintas teorías que explican el comercio internacional desde el campo de la economía. 
En la Tabla 1 se presenta la evolución de las teorías tradicionales que justifican el comercio entre países.

Se entiende por internacionalización el proceso de participación directa de la empresa en países y/o regiones geopolíticas distintas a las de su origen/sede, lo cual usualmente constituye un entorno económico diferente que demanda recursos y mayores exigencias de calidad, innocuidad, conocimiento, empaque, información del producto, servicio pos-ventas, innovación, tecnología, etc., y el diseño de una estrategia comercial que le permita a la empresa acceder a nuevos mercados, la mayoría de las veces, culturalmente diferentes y más competitivos que su entorno local.

TABLA 1. EVOLUCIÓN DE LAS TEORIAS TRADICIONALES DEL COMERCIO INTERNACIONAL.

\begin{tabular}{|c|c|}
\hline Teoría/autor/año & Aportaciones principales \\
\hline $\begin{array}{l}\text { Mercantilismo } \\
\text { (William Petty et al., 1690) }\end{array}$ & $\begin{array}{l}\text { Establecían que el oro y la plata eran los pilares fundamentales de la riqueza nacional y } \\
\text { esenciales para el comercio creciente. Petty formuló la ley de Petty-Clark, la teoría de la } \\
\text { renta diferencial y creo el término pleno empleo. }\end{array}$ \\
\hline $\begin{array}{l}\text { Ventaja Absoluta } \\
\text { (Adam Smith, 1776) }\end{array}$ & $\begin{array}{l}\text { Un país debe especializarse en la producción y exportación del bien que produce con } \\
\text { mayor eficiencia; con el menor número de horas de trabajo. }\end{array}$ \\
\hline $\begin{array}{l}\text { Ventaja Comparativa } \\
\text { (David Ricardo, principios del } \\
\text { siglo XIX) }\end{array}$ & $\begin{array}{l}\text { Aún si un país es más eficiente en la elaboración de dos productos, será relativamente } \\
\text { más eficiente en la producción de uno. Entonces, debe especializarse en la elaboración y } \\
\text { exportación de ese bien a cambio de la importación del otro. }\end{array}$ \\
\hline $\begin{array}{l}\text { Proporciones de factores } \\
\text { (Hecksher,1919; Ohlin, 1933) }\end{array}$ & $\begin{array}{l}\text { Si un país tiene abundancia de mano de obra (o de capital) debe especializarse en la } \\
\text { producción y exportación de bienes relativamente intensivos en mano de obra (o de capital). }\end{array}$ \\
\hline $\begin{array}{l}\text { Ciclo de Vida del Producto } \\
\text { (Vernon, 1966) }\end{array}$ & $\begin{array}{l}\text { La ventaja comparativa en la producción y exportación de un producto cambia con el } \\
\text { tiempo, conforme cambie la tecnología y avance el ciclo de vida del producto. }\end{array}$ \\
\hline $\begin{array}{l}\text { Nueva Teoría del Comercio } \\
\text { (Krugman, 1979) }\end{array}$ & $\begin{array}{l}\text { El comercio internacional, sobre todo entre países del mismo nivel de desarrollo, es } \\
\text { explicado por la existencia de competencia monopolística y de economías de escala } \\
\text { crecientes. Los mercados son imperfectos y se producen productos no homogéneos. Los } \\
\text { patrones del comercio son cambiantes, incluyendo el comercio intraindustrial. Todos los } \\
\text { factores de producción participan en mercados imperfectos. }\end{array}$ \\
\hline $\begin{array}{l}\text { Ventaja Competitiva } \\
\text { (Porter, 1990) }\end{array}$ & $\begin{array}{l}\text { La competitividad de una nación depende de la capacidad de su industria para innovar } \\
\text { y actualizarse. Las compañías ganan ventaja competitiva debido a la presión y al desafío; se } \\
\text { benefician de tener fuertes rivales domésticos, proveedores agresivos con sede en casa y } \\
\text { clientes locales exigentes. La ventaja competitiva también se establece a través de } \\
\text { "agrupamientos" (clústeres) geográficos o concentraciones de compañías en diferentes partes } \\
\text { de la misma industria. }\end{array}$ \\
\hline
\end{tabular}

Fuente: elaboración propia con información de Czinkota et al., 2005; y referencias citadas.

Lo anterior provoca que una compañía que decide exportar se beneficie no solo por el mayor nivel de ventas, sino por el conjunto de nuevos procesos, rutinas y exigencias consigo misma, que a la postre redundan en un aumento de la calidad, productividad y en una distinta cultura empresarial que la vuelven más competitiva, tanto en el mercado local como internacional.

Existen diversas definiciones de
internacionalización. Mientras unas
enfatizan sobre innovación, ventajas
específicas, gradualismo y reducción de

costos, otras definiciones hacen hincapié en la diversificación geográfica, evolución, cadena de valor, estructura organizativa, recursos humanos, entorno global y conocimiento aumentativo.

De acuerdo con Canals (1994), el proceso de internacionalización de las empresas involucra flujos comerciales de bienes y servicios ya sea en forma de exportaciones/importaciones o flujos de inversión directa.

$$
\text { Según Araya (2009) la }
$$
internacionalización es el proceso por el cual 
la empresa participa en una realidad parcial o totalmente diferente a su contexto local en un entorno internacional que genera flujos comerciales, financieros y de conocimiento.

La internacionalización debe también entenderse como un proceso gradual, compuesto por un conjunto de decisiones y actuaciones acumulativas que requieren de un intervalo de tiempo, generalmente amplio, lo que permite a la organización recorrer una serie de experiencias crecientemente complejas (Casillas, 1998).

Este proceso, además de tiempo, demanda decisiones estratégicas que implican planeación, conocimiento, recursos (humanos, materiales y financieros), capacitación, adecuaciones en la estructura organizacional y asumir nuevos riesgos.

Por consiguiente, Rave (2010:3) afirma que "la internacionalización de las empresas debe ser un proceso serio, pensado, analizado y bien estructurado, de tal manera que la inversión que exige el proyecto de conquistar nuevos mercados entregue los resultados deseados".

Desde la perspectiva de la economía evolutiva, la internacionalización debe entenderse como una estrategia corporativa que implica la diversificación geográfica internacional, la cual sigue un proceso evolutivo y dinámico que impacta gradualmente a toda la estructura organizativa de la empresa con un compromiso creciente de recursos y capacidades hacia el entorno internacional; todo en un proceso de conocimiento aumentativo (Villarreal, 2008).

Desde la misma óptica, Lam et al. (1999) ven esta etapa como un proceso gradual e innato en el cual la empresa avanza y adquiere mayor compromiso conforme incursiona en el mercado internacional.

Por su parte Armario et al. (2008), definen la internacionalización como un proceso de inserción gradual de bienes y servicios locales en los mercados internacionales siguiendo un proceso de aprendizaje, donde el conocimiento de los nuevos mercados y los recursos utilizados son cada vez más importantes. Estos mismos autores también reconocen que existen empresas que pueden ser internacionales desde su nacimiento (Born Global).

En el proceso de internacionalización, la empresa realiza una serie de actividades fuera de los mercados que constituyen su entorno geográfico local, sacando provecho de las tendencias globales que le traen ventajas productivas, financieras, logísticas, culturales, comerciales y de prestigio (Cuervo-Cazurra, 2004).

Las empresas que desean exportar deben tomar importantes decisiones sobre la estrategia a seguir para lograr con éxito su entrada al mercado internacional. Los cuatro modos más comunes de entrar directamente al mercado exterior son la exportación, licencia, joint venture y unificación (Agarwal et al., 1992).

No existen manuales infalibles en el proceso de internacionalización de las empresas. En un mercado cada vez más global y dinámico, todo cambia y se tienen que tomar muchas decisiones sobre el camino. La dificultad del proceso es mayor entre menor es el tamaño de la empresa. Muchos otros factores (recursos, conocimiento del mercado, productividad, barreras arancelarias y no arancelarias, entre muchos otros) influyen en el proceso, sobre todo en las PYMES. 
Las empresas buscan su internacionalización por diversas razones, las cuales pueden variar dependiendo de las condiciones internas y externas por las que esté pasando la compañía. Para Rueda (2008), estas razones pueden ser las siguientes: a) reducción de costos operativos, b) aprovechamiento de ventajas competitivas, c) condiciones económicas y jurídicas más favorables en un país extranjero, y d) necesidad de crecimiento a través de mercados emergentes. Por su parte Canals (1994) indica que los objetivos son la apertura de nuevos mercados, reducción de costos, aumentar las ventas y desarrollar una estructura de producción y distribución más eficiente.

Conforme las condiciones geopolíticas cambiaban y la guerra fría se acercaba a su fin, fue surgiendo una ola a favor de la diplomacia, la apertura y la globalización. Cada vez más países decidieron virar sus políticas económicas hacia modelos de apertura comercial y fortalecieron acciones en pro de la reducción arancelaria y la conformación de bloques comerciales como una estrategia para atraer inversión extranjera y mejorar su competitividad.

En sintonía con este proceso, aproximadamente a partir del último cuarto del siglo XX, también se inició el desarrollo de teorías y modelos académicos que intentaban explicar los mecanismos que seguían las empresas en su proceso de internacionalización.

$\mathrm{Al}$ respecto, no existe una teoría única que explique la complejidad que asumen las compañías en su proceso por llegar a mercados externos, sin embargo, coexisten algunos consensos a nivel global, por lo que se pueden agrupar desde, al menos, tres perspectivas: económica, de procesos $\mathrm{y}$ acelerada. La primera, describe la internacionalización como un fenómeno puramente basado en los costos y en las ventajas económicas que la misma implica; la segunda, analiza la internacionalización como un proceso secuencial de compromiso incremental basado en el aprendizaje, la acumulación de conocimientos $y$ en el aumento de recursos colocados en los mercados exteriores; la tercera, razona la internacionalización como una posibilidad que las empresas tienen, a pesar de su reciente creación, de que exporten una parte significativa de sus ventas totales (Ocampo, 2017). Un resumen de cada teoría, clasificada por perspectiva, se presenta en la Tabla 2.

\subsection{Modelo Uppsala}

El modelo de internacionalización Uppsala nace de los estudios realizados por Johanson y Wiedersheim (1975) y Johanson y Vahlne (1977, 1990). También conocido como escuela nórdica, caracteriza la internacionalización de las empresas como un proceso gradual y evolutivo donde la acumulación de experiencia es fundamental. Indica que las empresas primero se desarrollan en un mercado doméstico y que la internacionalización es producto de una serie de decisiones incrementales (Muriel, 2003).

Este modelo fue originalmente propuesto por la escuela nórdica para explicar los factores que impulsan la internacionalización de las empresas. Dichos autores tomaron como estudio empresas suecas para describir y analizar su proceso de internacionalización. 
TABLA 2. PRINCIPALES TEORfAS DE INTERNACIONALIZACIÓN DE LAS EMPRESAS, CLASIFICADAS POR ENFOQUE.

\begin{tabular}{|c|c|c|}
\hline \multicolumn{3}{|c|}{$\begin{array}{l}\text { Perspectiva Económica: Describe la internacionalización como un fenómeno puramente basado en los costos y en las ventajas } \\
\text { económicas de la misma. }\end{array}$} \\
\hline Teoría/autor (es) & Principales ideas & Críticas o limitaciones \\
\hline $\begin{array}{l}\text { Ventaja Monopolística } \\
\text { (Hymer, 1976) }\end{array}$ & $\begin{array}{l}\text { Para la inversión directa en el extranjero la empresa debe } \\
\text { poseer algún tipo de ventaja competitiva específica y } \\
\text { exclusiva que le permita competir lucrativamente con las } \\
\text { empresas establecidas en ese mercado. }\end{array}$ & $\begin{array}{l}\text { Tiene un carácter estático, lo que } \\
\text { provoca que se diga, en realidad, poco } \\
\text { acerca del proceso de inversión. }\end{array}$ \\
\hline
\end{tabular}

Internacionalización (Buckley y Casson, 1998)

Paradigma Ecléctico
(Dunning, 1980)
A partir del reconocimiento de la existencia de costos de transacción (consecuencia de los fallos del mercado), sostiene que la empresa realizará transacciones internacionales si los costos administrativos de dicha integración son menores que los costos de realizar las transacciones en el mercado local.

Combina las aportaciones de las teorías de la organización industrial, costos de transacción y las teorías de localización y del comercio internacional para afirmar que la empresa hará inversión directa en el extranjero cuando posea: ventajas competitivas específicas y exclusivas, decida internalizarlas en su estructura y además exista algún factor de localización, que motive la inversión.

Capacidades Organizativas La empresa puede llegar a la generación y sostenibilidad de (Madhok, 1997) ventajas competitivas en el exterior, sobre la base de una mayor eficiencia relativa a la hora de transferir internamente una determinada tecnología o conocimiento, lo que implica la introducción de un nuevo elemento en la decisión de internalizar una actividad, el costo en el que incurre la empresa en la transferencia interna del activo en cuestión. Dicho costo puede variar de unas empresas a otras independientemente de los costos de transacción surgidos del oportunismo.
Supone la capacidad de la empresa (en cuanto a dotación de recursos) para asumir, una vez que se identifique su conveniencia, el control de la entrada a mercados extranjeros. Condiciones que pueden ser asociadas con la gran empresa, no necesariamente con las Pymes.

Concentra su análisis en el proceso de la inversión directa en el extranjero, dejando de lado las otras posibles vías de internacionalización.

Resulta adecuado cuando se trabaja con empresas de gran tamaño, cuyas características, desafíos y ventajas resultan muy diferentes a las de las empresas Pymes.

\begin{tabular}{ll}
\hline $\begin{array}{l}\text { Perspectiva de Procesos: Analiza la internacionalización como un proceso secuencial de compromiso incremental basado en el } \\
\text { aprendizaje, la acumulación de conocimientos y en el aumento de recursos colocados en los mercados exteriores. }\end{array}$ \\
\begin{tabular}{lll} 
Teoría/autor (es) & Principales ideas & Críticas o limitaciones \\
\hline Modelo Uppsala (Johanson y & Las empresas inician sus operaciones en su mercado & Se considera excesivamente \\
Wiedersheim-Paul, 1975) & nacional, siendo la internacionalización una determinista, ya que no profundiza ni \\
& $\begin{array}{ll}\text { consecuencia directa de una serie de decisiones en los factores que influyen en el } \\
\text { incrementales. Las etapas de internacionalización deben proceso, ni en los problemas y }\end{array}$ \\
& de ser consideradas como un proceso global: 1) realizar & obstáculos que deben afrontar los \\
& exportaciones esporádicas; 2) exportación a través de gestores en el cambio organizacional.
\end{tabular}
\end{tabular}
representantes independientes; 3) establecimiento de sucursales comerciales en el extranjero; 4) establecimiento de unidades productivas en el extranjero.

Ciclo de Vida del Producto Relaciona la inversión directa en el extranjero con cada (Vernon, 1966) una de las etapas de la vida de los productos, mediante el análisis de las capacidades necesarias para competir en los mercados internacionales. De este modo, la inversión tiende a localizarse en los países con mejor dotación de los factores necesarios para competir en cada fase. 
Modelo de Innovación Centra su atención en la secuencia de aprendizaje en (Bilkey y Tesar, 1977) relación con la adopción de innovación. La decisión de internacionalización es considerada como una innovación para la empresa. Enfatiza especialmente las características del tomador de decisiones.

Redes (Johanson y Mattson, 1988)

\begin{abstract}
La internacionalización de la empresa vine determinada por una red de trabajo, la cual influye en sus actividades domésticas e internacionales. A través de la red se reduce la incertidumbre y los costos de buscar socios para entrar en nuevos mercados, y permite un mejor conocimiento de las oportunidades en el extranjero. Conforme la empresa se internacionaliza, aumenta el número de actores con los que interactúa, se dividen en: competidores, clientes, instituciones y entidades.
\end{abstract}

\begin{abstract}
Se ha criticado por ambigua $y$
\end{abstract} determinística.

Se centra solamente en un factor, la capacidad para el establecimiento de redes de trabajo y colaboración.

Perspectiva Acelerada: Razona la internacionalización como una posibilidad que las empresas tienen, a pesar de su reciente creación, de exporten una parte significativa de sus ventas totales.

\begin{tabular}{llll} 
Teoría/autor (es) & Principales ideas & Críticas o limitaciones \\
\hline Empresas Born & Global & Este tipo de organizaciones no espera obtener & Las investigaciones empíricas en este campo \\
(Knight y Cavusgil, 1996) & experiencia participando en mercados son incipientes, sin embargo, establecen \\
& internacionales como fuente de ventaja como una condición necesaria el uso \\
& $\begin{array}{l}\text { competitiva, sino que basa sus capacidades en el intensivo de tecnología y conocimiento por } \\
\text { conjunto de relaciones y conocimientos previos parte de la empresa. }\end{array}$ \\
& $\begin{array}{l}\text { que posee el empresario-fundador sobre las } \\
\text { actividades internacionales. }\end{array}$ \\
\hline
\end{tabular}

Fuente: Ocampo, 2017.

Johanson y Weidersheim (1975) asumen que la internacionalización es resultado de una serie de decisiones acumuladas conforme pasa el tiempo y que la empresa primero se desarrolla en el mercado nacional. Señalan como los principales obstáculos la falta de información y la escasez de recursos, lo que eleva la incertidumbre.

La concepción gradual del proceso se deriva de la decisión de la empresa de intentar primero incursionar en los mercados con menor "distancia psicológica" para posteriormente llegar a más complejos. La "distancia psicológica", además de cuestiones meramente de idioma, moneda, horario, empaque, etc., incluye la distancia geográfica, cultural y económica (Muriel, 2003).

Por su parte Johanson y Vahlne (1977) afirman que la internacionalización es el proceso gradual donde las operaciones internacionales se van realizando por medio de pequeños pasos, en vez de hacerse en una sola acción y con una gran inversión en el extranjero.

En este mismo sentido, Johanson y Weidersheim (1975) identifican cuatro etapas en el proceso de internacionalización: a) actividades no regulares de exportación, b) exportación vía representantes independientes, c) establecimiento de subsidiarias de venta en el exterior, y d) unidades de producción exterior.

En la primera etapa, se realizan actividades de exportación, esporádicas o irregulares. En donde la experiencia de la empresa es aún muy poca y no existe inversión alguna en el mercado destino por falta de información referente a ello.

La segunda etapa, se caracteriza porque la empresa ya cuenta con un agente o un representante por medio del cual realiza sus exportaciones. Este representante crea un canal de comunicación entre la empresa y el 
mercado a través del cual se empieza a tener conocimiento (aún escaso) de las condiciones del mercado externo.

Durante la tercera etapa, la empresa ya crea su propio canal de información a través de una oficina subsidiaria de ventas, permitiéndole esto un mejor control de la información que recibe del mercado. Además, acumula una mayor experiencia de todo el proceso de ventas y una diferenciación sobre sus competidores.

En la cuarta etapa, la empresa ya tiene mucha más información sobre factores específicos de ventas y producción en el país destino. Ya no solo tiene un control sobre las ventas en los mercados externos, sino también un control sobre su producción en el país destino, dado que la empresa ya ha decidido invertir directamente en una planta extranjera.

El centro neurálgico del modelo Uppsala radica en aceptar que gran parte de las capacidades necesarias para el proceso de internacionalización de las empresas se van obteniendo mediante un proceso de aprendizaje experimental. $O$ sea, es un proceso gradual y secuencial donde se va desarrollando un compromiso con el mercado exterior (Melin, 1992).

Por consiguiente, podemos deducir que la transición de una empresa nacional a internacional, generalmente se lleva a cabo de manera gradual. Durante este proceso, la empresa comienza a tener un grado de responsabilidad y compromiso cada vez mayor conforme aumenta su conocimiento sobre el mercado externo, así como de las variables propias del proceso.

Los mismos autores (Johanson y Wiedersheim (1975), Johanson (1977) y
Vahlne (1990)) afirman que el gradualismo no se cumple en las grandes empresas que disponen de recursos suficientes y/o pueden acceder a esquemas favorables de financiamiento. Entonces, el modelo explica básicamente el comportamiento de las pequeñas y medianas empresas o de aquellas que se encuentran en etapas tempranas de su internacionalización, no de las grandes empresas. Los autores también reconocen que, en mercados muy homogéneos y estables, donde el conocimiento puede ser adquirido por otras vías que no son necesariamente la experiencia, el modelo carece de cierta fuerza explicativa.

En ese sentido, el modelo registra algunas críticas como la relación directa entre el creciente conocimiento de los mercados y el mayor compromiso internacional. Otra crítica es la linealidad del modelo ante una realidad dinámica y compleja, que no toma en cuenta la interdependencia que pudiera existir entre los diferentes mercados, ya que los trata como si fueran completamente independientes. Además, este modelo no es útil al tratar de explicar la oferta de servicios, como es el caso de la internacionalización de la banca (Muriel, 2003).

No obstante, las críticas al modelo Uppsala ha sido muy socorrido para la explicar la internacionalización de empresas en diferentes regiones del mundo. Incluso, se han hecho adaptaciones combinándolo con la Teoría de Recursos y Capacidades (TRC) de Wernerfelt (1984). La TRC se observa como una muy buena opción para explicar los determinantes del desempeño empresarial, incluido el proceso de internacionalización y la innovación, dado que establece que los recursos y capacidades de la empresa no se comportan según los supuestos de la competencia perfecta, lo que implica que el 
éxito de las organizaciones se debe a la gestión eficiente de sus recursos individuales y a la relación que ellas establecen entre los recursos, las capacidades, la ventaja competitiva y los beneficios extraordinarios de largo plazo (Fong, 2017).

Una combinación de estas teorías (modelo Uppsala y TRC) para explicar la internacionalización de las empresas de los países emergentes la utiliza Ocampo et al. (2014), los cuales analizan los determinantes del proceso entre modelos acelerados $y$ secuenciales, concluyendo la posibilidad de realidades locales mixtas entre ambos extremos.

La figura 1 muestra este modelo híbrido que debe ser leído de izquierda a derecha, donde la primera línea describe las etapas secuenciales de internacionalización de la empresa de acuerdo con el modelo Uppsala, en la segunda línea se anotan las capacidades individuales con las que debe contar la empresa en cada etapa de acuerdo con la TRC, mientras que en la tercera línea se anotan los recursos que soportan esas capacidades en cada epata de acuerdo también con la TRC.

\subsection{Teoría de la integración económica}

Según Reyes (2008) la teoría de la integración económica se puede dividir cronológicamente en dos momentos. El primero, de 1950 a 1979 , al cual denomina teoría de las uniones aduaneras. El segundo, de 1980 en adelante, al cual denomina teoría de los bloques.

Los países realizan una serie de gestiones hacia la integración con otras economías. Dichas operaciones se llevan a cabo mediante etapas o procesos de negociación. Para Balassa (1964), la integración equivale a la eliminación de las barreras artificiales que obstruyen el flujo permanente de la actividad económica a través de fronteras nacionales.

La integración de los países es un proceso complejo que trae consigo no solo aspectos comerciales, sino políticos, laborales, empresariales, académicos, culturales y ambientales. Este proceso consta de varias etapas, el cual determina el grado de acercamiento y de complementariedad entre las economías participantes. Generalmente, los países interesados sobre una potencial integración establecen vínculos a través del movimiento de bienes, servicios y factores de producción (Czinkota et al., 2005).

La integración económica no necesariamente se lleva a cabo entre países vecinos. Según la CEPAL (2014), los países buscan encontrar ventajas arancelarias y no arancelarias con otras naciones, independientemente de su ubicación geográfica. El objetivo general de los acuerdos es reactivar el comercio internacional y el crecimiento económico de las naciones involucradas, volviendo a la región más competitiva respecto al resto del mundo.

La integración económica tiene diferentes grados (Figura 2). La "zona de libre comercio" es la primera etapa de integración. En ésta, los países signatarios llegan a un común acuerdo de libre intercambio comercial. Cada país cuenta con su política aduanera y tiene como fin la desgravación arancelaria hasta llegar a un arancel cero. Generalmente, para la mayoría de las mercancías (80-90\%) se acuerda la eliminación inmediata de su arancel, mientras para el resto se programa su reducción hasta llegar a cero. 
FIGURA 1. PROCESO HIBRIDO DE INTERNACIONALIZACIÓN DE EMPRESAS ENTRE MODELO UPPSALA Y TEORIA DE RECURSOS Y CAPACIDADES (TRC).

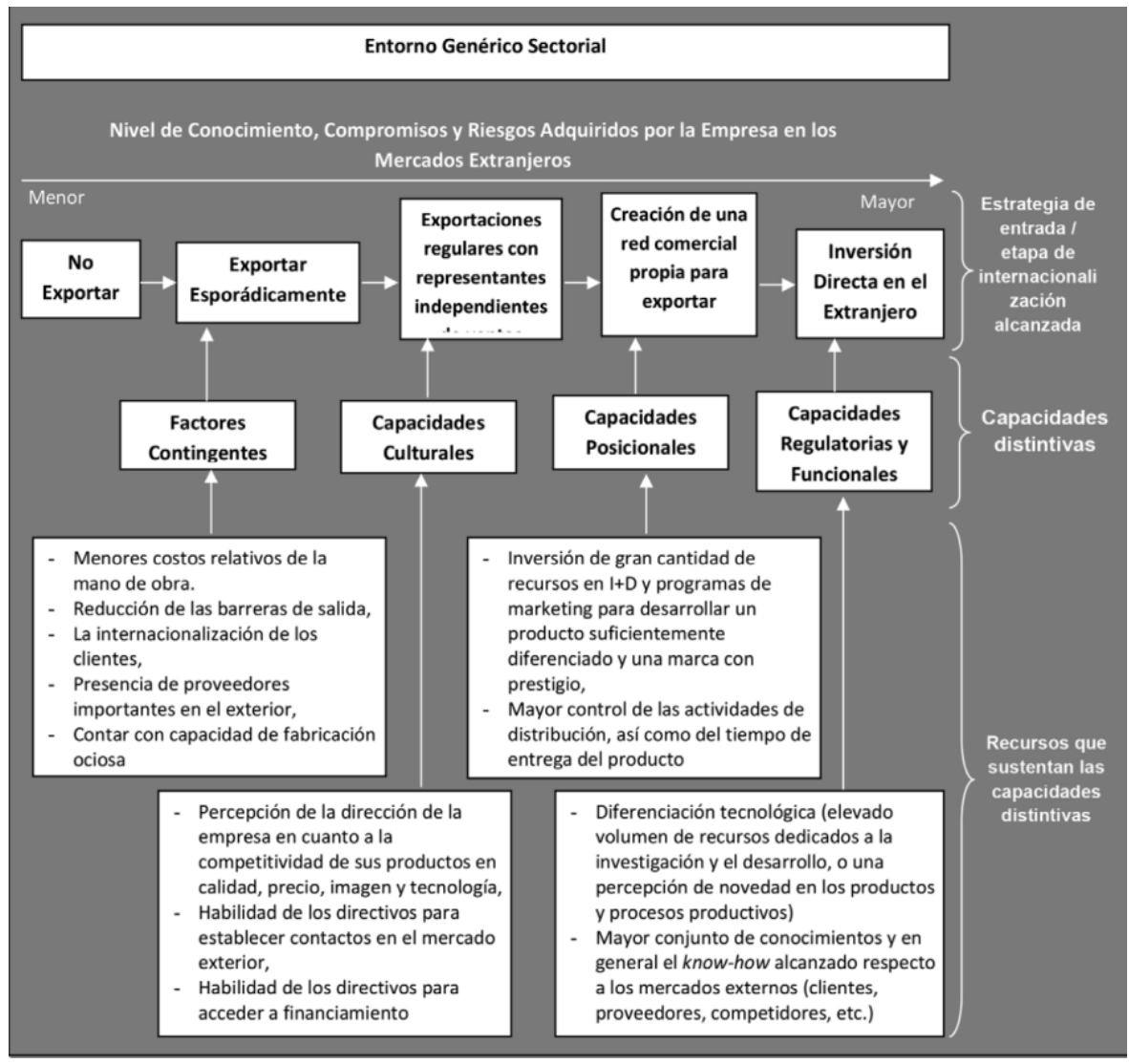

Fuente: Ocampo, Alarcón y Fong, (2014), Determinants of the internationalization of the firm: the accelerated model vs the sequential model. The International Journal of Business and Finance Research, 8(5), pp. 88-93.

También se negocia la eliminación/reducción sobre barreras no arancelarias y demás procedimientos normativos, lo que facilita el intercambio comercial. Los acuerdos únicamente son válidos entre las economías firmantes, manteniendo cada país sus propios aranceles al resto del mundo.

La "unión aduanera" es la segunda etapa de integración. En este caso, además de eliminar los aranceles, se establece un arancel externo común entre los firmantes del acuerdo, mismo que es aplicado al resto de las naciones no firmantes. El sistema aduanal de los firmantes tiene una misma política comercial frente a otros países (Kim, 2009).
El "mercado común" es la tercera etapa de asociación. Además de lo precedente, ésta incluye el libre tránsito de personas y capitales entre los países firmantes. Las personas no requieren visa para su movilidad entre las naciones socias y existen facilidades para el trabajo y estudio. Lo anterior, incrementa la inversión extranjera directa de las empresas y facilita la movilidad de mano de obra.

La "unión económica" es la cuarta etapa de integración. Incluye la coordinación de política monetaria y fiscal entre los países miembros, para lo cual se requiere crear instituciones que instrumenten y supervisen dicha coordinación, como son un banco 
central y una moneda única. El ejemplo más acabado de este tipo de integración es la Comunidad Económica Europea.

La "integración económica completa" es la quinta etapa. Representa la cúspide de la integración e implica la existencia de un poder supranacional que limita la independencia política y social de los países socios, a cambio, se supone, de beneficios mayores que se derivan de dicha integración. En la práctica, este tipo de agrupación no existe y no hay manera de comprobar si fuera benéfica. Balassa (2011) presupone que la unificación de políticas monetaria, fiscal, social y anticíclica requiere del establecimiento de una autoridad supranacional cuyas decisiones son vinculantes con los países miembros.

FigURA 2. TIPOS DE INTEGRACIÓN ECONÓMICA.

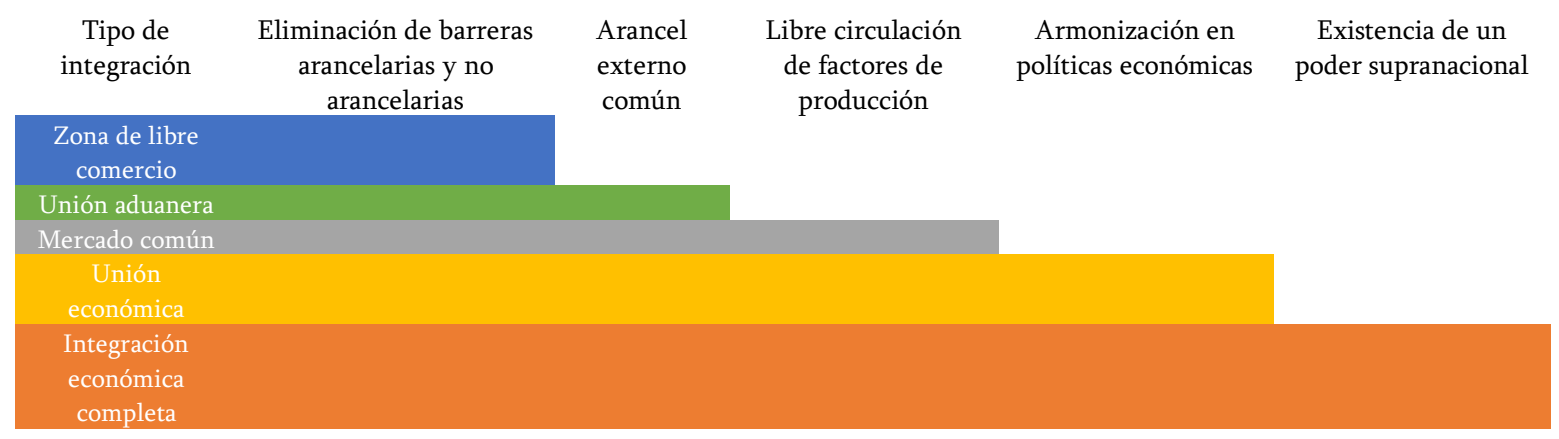

Fuente: elaboración propia con información de Kim (2009), Kirchner (2000) y Balassa (2011)

\section{Metodología}

El análisis empírico se realizó en dos niveles, uno específico y otro general. El análisis específico, fue un caso de intervención a una empresa local cuyo requisito principal fue que estuviera exportando, al menos, a un país de la AP. El análisis general, fue una consulta al sector exportador local, independientemente de si la empresa estaba exportando o no hacia algún país de la AP. Para el primer nivel se usaron métodos directos de investigación de campo como son entrevistas semiestructuradas a las diferentes áreas de la empresa que se determinó influyeron en su proceso de internacionalización; mientras para el segundo nivel se realizaron entrevistas a una muestra representativa del sector exportador. En ambos casos, el objetivo fue obtener elementos de campo que nos permitieran validar la hipótesis.
Los criterios para seleccionar el estudio de caso fueron: a) que la empresa realizara actividades de exportación hacia algún país miembro de la AP; b) que fuera una empresa registrada en el directorio de exportadores del Estado de Sinaloa; y, c) que fuera una empresa líder en su ramo por el valor de las exportaciones.

Con esos criterios, la empresa seleccionada fue "Jova Graneros S.A. de C.V.", fundada en 1983, con sede en el valle de Culiacán, Sinaloa, México. La empresa se dedica al acopio, almacenamiento, procesamiento y comercialización de granos agrícolas como son maíz, sorgo, frijol, trigo y garbanzo. Cuenta con 15 sucursales en el Estado de Sinaloa y 4 en Sonora, su mayor movimiento es de maíz y garbanzo, de los cuales comercializa aproximadamente 400 mil y 45 mil toneladas, respectivamente. 
Los servicios que presta la empresa a los productores primarios son: 1) financiamiento agrícola, 2) venta de agro-insumos y asesoría técnica, 3) centro de acopio, 4) comercialización nacional e internacional de granos, 5) coberturas y agricultura por contrato, 6) solución de logística y transportación. La información obtenida y analizada fue de los últimos seis años de operación de la empresa, auscultando de sobremanera la información relacionada con los países miembros de la AP. La empresa registró exportaciones durante los últimos años a los tres países miembros del tratado (Chile, Colombia y Perú), destacando que la empresa exporta el $40 \%$ del garbanzo producido en México, mismo que es embarcado a través del puerto de Mazatlán con destino a diversos países como Turquía, Argelia, Emiratos Árabes Unidos, Colombia, entre otros. La intervención en la empresa por nuestra parte duró aproximadamente seis meses (julio-diciembre, 2017).

Para el nivel de análisis general, se eligió una muestra representativa de empresas tomando como universo el total de empresas inscritas en el directorio de exportadores de Sinaloa. Dado que el directorio enlista a todas las empresas sinaloenses que realizan exportaciones, sin distinguir si dichas exportaciones son ocasionales o frecuentes, se requirió aplicar algunos filtros que hicieran más uniforme nuestro universo. Los filtros fueron: a) que la antigüedad mínima de la empresa como exportadora fuera de seis años; b) que el tamaño de la empresa fuera pequeña o mediana, de acuerdo con la estratificación de la Secretaria de Economía; c) que la empresa estuviera catalogada como altamente exportadora; y, d) que la empresa perteneciera al mismo sector que el caso de la empresa estudiada (agroindustrial).
La muestra de empresas fue determinada por medio de la siguiente formula (Psyma, 2017):

$$
n=\frac{N \cdot Z^{2} \cdot p \cdot q}{(N-1) \cdot e^{2}+Z^{2} \cdot p \cdot q}
$$

Donde:

$\mathrm{n}=$ tamaño de la muestra a estimar.

$\mathrm{N}$ = tamaño de la población

$\mathrm{Z}=$ desviación del valor medio aceptado para el nivel de confianza deseado.

$\mathrm{e}=$ margen de error.

$\mathrm{p}=$ variabilidad positiva .

$\mathrm{q}=$ variabilidad negativa, $1-\mathrm{p}$.

Suponiendo un nivel de confianza del $95 \%$, un error del $10 \%$, una variabilidad negativa y positiva de 0.5 , se estimó una muestra de 23 empresas a consultar. Dada la baja disposición a proporcionar información por parte de las empresas exportadoras, se utilizó el método no probabilístico por conveniencia para seleccionarlas, mecanismo estadístico que permite sustituir a una empresa seleccionada que no desea proporcionar información, por otra que si esté dispuesta a hacerlo. El período de aplicación de encuestas fue de dos meses (septiembre-octubre, 2017), contactando a las empresas vía telefónica y utilizando la herramienta de google docs. Adicional a la muestra se incluyó a dos líderes del sector gubernamental con la idea de obtener, desde la perspectiva oficial, el impacto de este acuerdo comercial en las exportaciones sinaloenses.

Para el procesamiento y análisis de la información, tanto de la empresa intervenida como de las encuestas al sector exportador, se utilizó el software atlas.ti (Scientific Software Development GmbH, 2017). El uso de esta 
herramienta permitió la estructuración y agrupación de información relevante, destacando los lazos entre una entrevista y otra, así como a encontrar coincidencias y divergencias entre los entrevistados.

\section{RESULTADOS Y DiSCUSIÓN}

La AP a partir de su creación ha fomentado la cooperación internacional entre las cuatro naciones. Se han realizado 13 cumbres en las cuales se han presentado los avances y problemas del acuerdo. Sobresalen los esfuerzos de coordinación para apoyar a las PYMES, apoyos a emprendedores, promoción turística, promoción de inversiones, encuentros empresariales, apoyos para para movilidad de jóvenes, intercambios académicos, negociaciones con otros países para sumarlos al acuerdo (Australia, Canadá, Nueva Zelanda y Singapur), así como acercamientos y coordinación con los países miembros del Mercosur (Argentina, Brasil, Paraguay y Uruguay).

A continuación, se presentan los resultados conforme a los dos niveles en que fue planeada y llevada a cabo esta investigación: caso de estudio y consulta al sector exportador de Sinaloa.

\subsection{Caso de estudio}

En el análisis empresarial llevado a cabo al interior de la compaña se encontraron evidencias sobre el aprovechamiento de las ventajas contenidas en la AP. Fue en el marco de este acuerdo comercial que Jova Graneros decidió explorar nuevos mercados, identificando clientes y oportunidades que a su juicio podía aprovechar.

Para lo anterior, se analizaron las estadísticas de exportación de la empresa, las cuales muestran un aumento paulatino en el período analizado (2012-2017), destacando por su valor y volumen el mercado de Colombia. A decir de los directivos de la empresa, con el paso de los años existe una confianza mayor por parte de los compradores tanto colombianos como chilenos, dado que existe un incremento en sus volúmenes de compra y un creciente número de empresas que están adquiriendo los productos.

Cabe destacar que la internacionalización de Jova Graneros fue un proceso gradual. Inició con exportaciones ocasionales, continuando con un trabajo de identificación de posibles clientes en los distintos países y haciendo las exportaciones correspondientes. Después procedió a asistir a ferias internacionales, medio por el cual consiguió parte de sus clientes que actualmente han crecido en número y volumen.

Resultado de las entrevistas y del conocimiento directo de los procesos de la empresa, encontramos una actitud proactiva en todo el personal sobre la importancia de conocer el mercado internacional y las ventajas que potencialmente ofrecen los tratados comerciales que México tiene signados con el exterior. Específicamente sobre el tratado que nos ocupa, se detectaron áreas de oportunidad donde, de acuerdo con la empresa, las autoridades pueden mejorar.

Según la empresa, existe un bajo nivel de difusión de los tratados comerciales por parte de las instancias gubernamentales, tanto federales como estatales. "ProMéxico hace varias reuniones al año, generalmente nos avisan y asistimos, pero sentimos que no hacen lo suficiente. Por ejemplo, viene el representante de ProMéxico en Japón y/o Rusia a dar una conferencia y termina diciendo que es cuestión de que las empresas 
se acerquen a las oficinas. Pero precisamente ese es el problema, uno es el que siempre tiene que ir a buscarlos. En la práctica, las dependencias no se acercan a las empresas para incentivar las exportaciones".

Señala la compañía, que no existe una iniciativa por parte de las autoridades locales para ofrecer información sobre compradores en el extranjero u oportunidades de negocio. "Uno los tiene que buscar y, en ocasiones, hasta ellos mismos las desconocen", indicaron.

Otra área donde faltan apoyos es en ferias internacionales. No obstante que son un buen instrumento de promoción, dichos apoyos son muy escasos, señalaron. Reconociendo que Jova Graneros ha recibido apoyos para su asistencia a eventos internacionales, sienten que este tipo de subsidios se han venido reduciendo en los últimos años, mientras los costos de asistencia han venido aumentando. Sin embargo, la empresa está dispuesta a continuar sus esfuerzos para invertir en este tipo de promoción.

Desde la perspectiva de Jova Graneros, debe existir una búsqueda constante de nuevos mercados. En su caso particular, los mercados de Sudamérica implican oportunidades de negocio en el marco de la AP. Un ejemplo de ello es Colombia, país que antes no era un comprador de garbanzo procedente de México, pero que a partir de la desgravación arancelaria empezó a demandar este grano.

Usualmente cada empresa tiene una percepción distinta sobre los esfuerzos requeridos para su internacionalización. En general, la empresa tiene un mayor control sobre variables internas como son costos, insumos, calidad y recursos humanos; no así sobre variables externas como son precios, restricciones arancelarias y no arancelarias, logística de exportación, etc.

En el primer aspecto, Jova Graneros incrementó su eficiencia y calidad, estandarizando todos sus procesos y capacitando al personal; mientras en el segundo, buscó los beneficios comerciales incluidos en la AP. Debemos decir que el tratado incluyó desde su inicio (2012) una desgravación arancelaria de cero por ciento para el $92 \%$ de las mercancías, mientras el resto tiene un calendario de desgravación que implica que para el 2022 el 100\% del comercio entre las cuatro naciones estará libre de arancel. También contempla facilidades en trámites aduanales y una homogeneidad en los procesos de desaduanamiento, entre otros beneficios.

Con el fin de fortalecer las relaciones entre empresarios y crear un mayor flujo de bienes y servicios entre las naciones, como lo mencionan Czinkota, et al., (2005), la propia integración incluye acuerdos para establecer vínculos de inversión, así como de factores de producción a través de las fronteras.

La AP ofrece estos vínculos para que tanto empresarios de gran trayectoria como emprendedores puedan conocer y obtener ventaja de todas las oportunidades y los mecanismos de los países miembros. Por ejemplo, incluye programas para movilidad de personas, becas a jóvenes, intercambio académico, construcción de infraestructura conjunta, etc. Lo anterior también coincide con lo dicho por Ceballos (1971), quien refiere que la integración económica de una región implica la creación de vínculos y cooperación más allá del ámbito estrictamente comercial.

Sobre la manera que la AP ha impactado las exportaciones de la empresa, la compañía 
indicó que el volumen de éstas creció en años recientes y que este hecho se debe a las oportunidades que se abrieron a partir del tratado.

La búsqueda de clientes potenciales es una tarea bastante importante para las empresas por lo que cualquier actividad, que desde el ámbito gubernamental se pueda realizar, en ese sentido es bienvenida, afirmó la compañía.

Existen diversos obstáculos no arancelarios en el proceso de exportaciones. En la parte logística es muy importante el manejo de las mercancías, los procesos aduanales, contratos, seguros, fianzas, normatividad, carga, descarga, manejo de conflictos, entre otros. $\mathrm{Al}$ respecto la empresa, seguramente por su perfil agroindustrial, identifica los mayores obstáculos en las áreas de regulaciones fitosanitarias, manejo de la carga, certificado de origen, falsificación de marca, normatividad portuaria, entre otras. Por ejemplo, "el certificado de origen y la interpretación de su contenido depende del país destino. Algunos países requieren que el certificado diga tal o cual frase que los haga sentir seguros de que la mercancía pasó por ciertos procesos de sanidad y calidad. La marca en nuestros costales es un arma de doble filo; es bueno, dado que nuevos clientes pueden contactarnos; es malo, porque pueden ser rellenados con producto de baja calidad y hacerlo pasar como nuestros".

De acuerdo con Rave (2010) la internacionalización de la empresa es un proceso planeado, analizado y gradual, con resultados sólidos únicamente a mediano y largo plazo, situación que concuerda con la realidad vivida en Jova Graneros.
Una ventaja que observó la empresa para decidir incursionar en los países miembros de la AP son las similitudes en idioma, base alimenticia, estándares de calidad, normatividad y características culturales, ya que no se requieren grandes cambios o adecuaciones en el producto y su empaque.

En el proceso de investigación se observó que la empresa $y$ los funcionarios gubernamentales entrevistados no tenían conocimiento sobre actividades pasadas, presentes o futuras de difusión/capacitación sobre la AP, lo anterior viene a confirmar la falta de una estrategia promocional definida sobre este tratado.

En el periodo analizado la empresa ha consolidado sus exportaciones a los mercados sudamericanos. "No hay muchas empresas que exporten hacia esos países. Somos pocos los que nos hemos posicionado en esos mercados. En nuestro caso, el mercado de Colombia es donde mayormente hemos crecido", indicó.

Pudimos comprobar que a partir de la entrada en vigor de la AP la empresa aumentó considerablemente sus ventas hacia esos países. En general, ellos creen que su participación en ferias y misiones comerciales internacionales les ha permitido ampliar sus horizontes e incrementar su cartera de clientes. Por lo anterior, recomiendan ampliamente al resto de empresas su participación en este tipo de eventos, aunque ellos desconocen si existen apoyos específicos para el caso de los países firmantes de la AP.

Comparando los resultados encontrados sobre el proceso de internacionalización de Jova Graneros con las aportaciones teóricas de Villarreal (2008), el cual afirma que las empresas siguen estrategias definidas para su diversificación geográfica como un proceso 
evolutivo que gradualmente afecta todas las actividades y estructura del organismo, se afirma que se cumple dicha teoría en este caso.

En el proceso de internacionalización de la empresa, cada nuevo nivel alcanzado implica un grado mayor de compromiso con el mercado destino. En la intervención, se encontró un aprendizaje experimental sumado a un compromiso empresarial con el mercado exterior, como lo propone Melin (1992).

\subsubsection{Sector exportador}

Del total de entrevistadas aplicadas, el 85.7\% afirmaron contar con un área exclusiva de comercio internacional dentro de la empresa. Mientras que el resto (14.3\%) dijeron no contar con un área definida de carácter internacional (ver figura 3). Lo anterior evidencia que la mayoría de las empresas que realizan comercio exterior, por necesidad y/o estrategia, establecen dentro de la compañía un área especializada para atender este tipo de negocios.

FIGURA 3. EMPRESAS QUE CUENTAN CON UN ÁREA DE COMERCIO INTERNACIONAL.

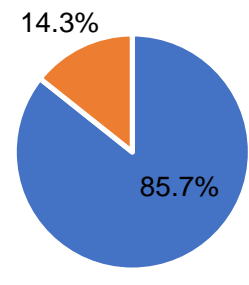

$$
\text { - Si }=\text { No }
$$

Fuente: elaboración propia.

Con el objetivo de conocer el nivel de internacionalización que observan las empresas, se les cuestionó sobre la forma que realizan sus exportaciones y si cuentan con oficinas en el exterior. El 56.5\% afirmó que exportan de forma directa y sin intermediarios, mientras que el $39.1 \%$ aún sigue exportando de manera indirecta. Además, sólo el $4.3 \%$ cuenta con oficinas de distribución en los países destino (ver figura $4)$.

FIGURA 4. NIVEL ACTUAL DE INTERNACIONALIZACIÓN DE LA EMPRESA.

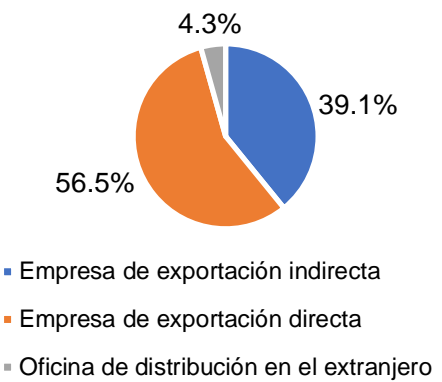

Fuente: elaboración propia.

La figura 5 muestra los motivos que llevaron a las empresas incursionar en el mercado internacional. El $47.8 \%$ de las empresas inició exportaciones por la existencia de clientes internacionales, el $21.7 \%$ lo hizo motivado por aprovechar las ventajas de algún tratado comercial firmado por México, mientras que otro $21.7 \%$ lo hizo motivado por la idea de diversificar su riesgo, en tanto el $8.7 \%$ de las empresas lo hizo por contar con capacidad ociosa de producción.

FIGURA 5. MOTIVO DE LA INTERNACIONALIZACIÓN.

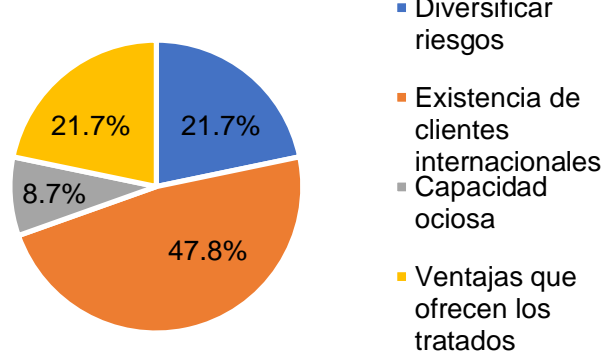

Fuente: elaboración propia.

La concentración de las exportaciones hacia el mercado de Estados Unidos fue corroborada por las entrevistas, aunque en un 
porcentaje menor que el generalmente estimado por la literatura. Se encontró que el $52.2 \%$ de las empresas locales exportan sus productos a Estados Unidos, el $17.4 \%$ a Europa (destaca Alemania, España, Francia y Medio Oriente), el 13\% a Canadá, el 8.7\% a Japón, el $4.3 \%$ a países de África (principalmente Argelia) y el $4.3 \%$ a Centroamérica. Del total de la muestra, destaca que ninguna empresa exporta a Sudamérica, situación que evidencia la poca atención que se presta a las oportunidades, que seguramente existen, en esos mercados para los productos locales (ver figura 6). Lo anterior muestra que, al menos en las empresas exportadoras de Sinaloa, específicamente las del sector agroindustrial y de tamaño pequeña y mediana, la concentración de las exportaciones hacia Norteamérica (65\%) es menor que el promedio nacional (80\%). Inicialmente, esto es un punto favorable para la economía de Sinaloa dada la apremiante necesidad de diversificar su comercio exterior.

FIGURA 6. DESTINO DE LAS EXPORTACIONES.

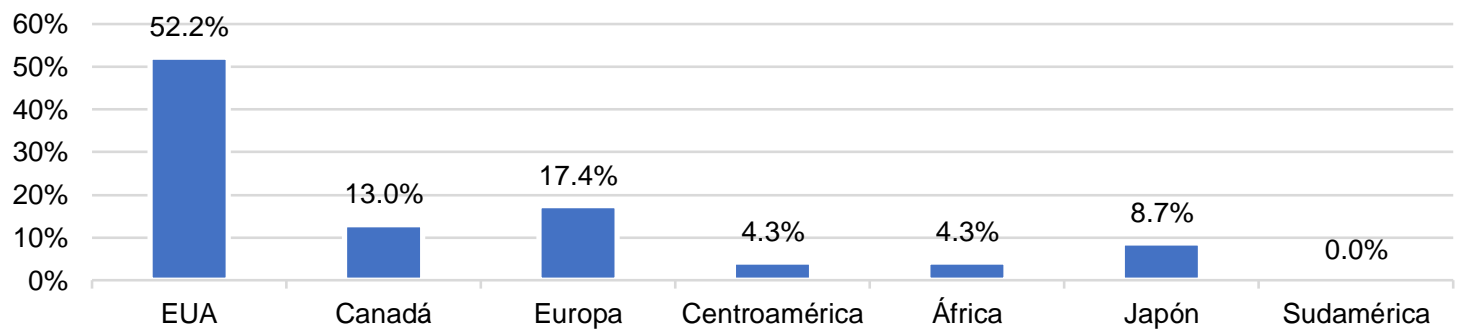

Fuente: elaboración propia.

Una pregunta neurálgica de la encuesta es la referente al nivel de conocimiento por parte de la empresa sobre los tratados comerciales ya que en función de ello se podría inferir su aprovechamiento. En general, el nivel de conocimiento de los tratados comerciales es muy bajo, exceptuando el TLCAN, el cual más del 50\% de las empresas exportadoras dijeron conocer ampliamente. Esto último se explica por la ubicación geográfica de los países socios del tratado, tamaño de mercado, integración de las economías y antigüedad del tratado (1994); pero lo que no se entiende, es el bajo aprovechamiento de las oportunidades que ofrecen el resto de los tratados comerciales, específicamente la AP. Se supondría que tenemos fuertes afinidades de idioma, cultura, gustos, entre otros aspectos, con Chile, Colombia y Perú, por lo que el comercio con esas naciones debería estar creciendo, sobre todo, a raíz del tratado comercial que se firmó con esas naciones. Solo el $9.5 \%$ de las empresas dijo tener conocimiento de este tratado y que lo conocían por iniciativa propia, no porque las agencias gubernamentales lo hayan promovido entre el sector exportador.

Esto quiere decir, que más del $90 \%$ de las empresas exportadoras desconoce la AP, por lo que ignoran los beneficios específicos que pudiera acarrear este tratado para sus compañías. El reto por supuesto de todos los entes involucrados, autoridades federales y estatales, agencias promotoras de las exportaciones, universidades y organismos empresariales, es promover este instrumento de comercio exterior para mejorar su aprovechamiento y aumentar las exportaciones y la diversificación de estas, 
situación que a la postre traería beneficios para toda la economía local.

Para confirmar los resultados anteriores, preguntamos a las empresas si alguna de ellas había exportado a los países miembros de la AP. Se encontró que ninguna de ellas lo ha hecho, lo que concuerda con el grado de desconocimiento sobre este acuerdo comercial. Además, las empresas que afirmaron conocer el tratado (9.5\%), también declararon conocerlo "muy poco".

A pregunta expresa sobre si las autoridades gubernamentales habían promovido la AP ante ellos, el $100 \%$ de las compañías entrevistadas dieron una respuesta negativa, aunque el $76 \%$ aceptó que al menos una vez han recibido la visita de alguna dependencia gubernamental con el fin de incentivar sus exportaciones, pero que en dicha visita no recibieron información sobre este tratado comercial y sus ventajas.
De lo anterior se infiere que existe un fuerte problema de conocimiento de la AP entre las empresas exportadoras locales y un problema de promoción de este, lo que nos conduce a comprobar la hipótesis de este artículo.

A las empresas que dijeron haber recibido al menos una visita por parte de las autoridades encargadas de promover las exportaciones, se les cuestionó sobre el tipo de información/apoyo recibido. Los servicios más mencionados fueron asesoría legal y gestoría económica con un $26 \%$ cada uno, seguido de asesoría comercial con un 13\% y asesoría logística con el 9\%. Destaca que el $26 \%$ de las empresas afirmaron no haber recibido nunca ningún tipo de apoyo de las autoridades, y cuando ellos mismos se han acercado en búsqueda de apoyos, no se les ha proporcionado por diversas cuestiones. Este porcentaje representa un área de oportunidad para mejorar los servicios por parte de las autoridades gubernamentales (ver figura 7).

FIGURA 7. TIPO DE APOYO RECIBIDO POR EL GOBIERNO.

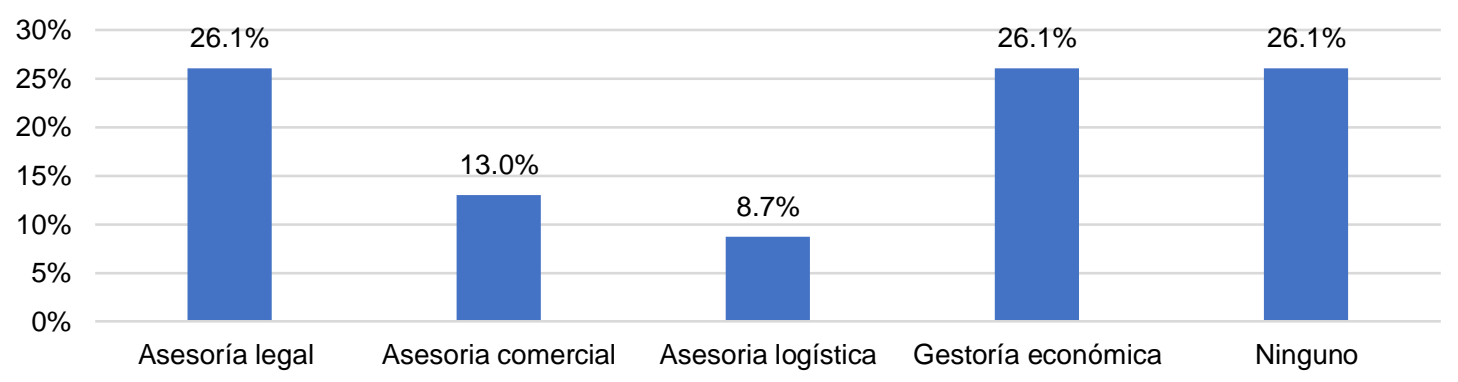

Fuente: elaboración propia.

Aproximadamente el 80\% de las empresas calificaron el apoyo ofrecido por parte de las dependencias de gobierno entre bueno y regular, el resto lo calificó como malo. Específicamente el 38\% calificó el servicio que reciben como bueno, el $42 \%$ como regular y el $20 \%$ como malo. Lo anterior implica que existe un amplio margen de mejora en el servicio, las autoridades pudieran aprovechar esto para difundir más información y promoción de los tratados comerciales como la AP.

Según la Organización para la Cooperación y el Desarrollo Económico (OECD, por sus siglas en inglés) las barreras a 
las cuales se enfrentan las PYMES cuando desean internacionalizarse son: 1) escasez de capital de trabajo para financiar exportaciones; 2) identificar oportunidades de negocios en el extranjero; 3) información limitada para localizar/analizar mercados; 4) incapacidad para contactar potenciales clientes extranjeros; y 5) falta de tiempo gerencial, habilidades y conocimiento (OECD, 2009).

Con el objetivo de investigar las razones específicas de esos problemas entre las empresas de Sinaloa, preguntamos sobre los motivos principales que inhiben su proceso de internacionalización. Como se puede observar en la figura 8, el $50 \%$ señaló obstáculos financieros (barrera 1 de la OECD), 22\% preparación de personal (barrera 5 de la OECD), 11\% problemas comerciales (barrera 2 de la OECD), 8\% problemas de falta de apoyo gubernamental (barrera 3 de la OECD), 6\% problemas logísticos (barrera 4 de la OECD) y 3\% problemas fiscales.

En general, los resultados encontrados evidencian la falta de promoción de los tratados comerciales $y$ sus ventajas, específicamente la AP. En nuestra búsqueda de información tampoco encontramos documentos oficiales que analicen las razones por las cuales las empresas a nivel local no están aprovechando las ventajas comerciales que ofrece la AP.

Este es otro déficit de las entidades gubernamentales encargadas de promover el comercio exterior, dado que en la medida que se conozcan esas razones, se pudieran implementar acciones que reviertan dicho problema. En tiempos de alta incertidumbre comercial y de mayor globalización, como los actuales, una estrategia altamente recomendable es la diversificación de los mercados destino de las exportaciones de México.

FIGURA 8. BARRERAS QUE REPRESENTAN OBSTÁCULO PARA LA INTERNACIONALIZACIÓN DE LA EMPRESA.

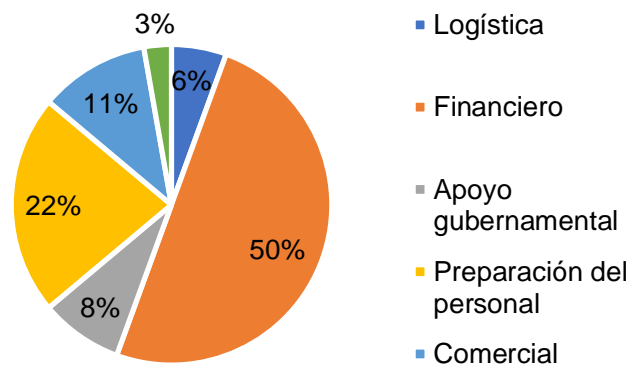

Fuente: Elaboración propia.

Finalmente, hemos llegado a la comprobación de la hipótesis de la investigación, la cual presupone que las ventajas comerciales que ofrece la AP están desaprovechadas por parte de las empresas exportadoras de Sinaloa, evidenciando la falta de una estrategia de internacionalización de las empresas hacia esos mercados y una falta de promoción de dichas ventajas por parte de las autoridades gubernamentales.

\section{CONCLUSIONES}

La AP es un importante tratado comercial entre México, Colombia, Chile y Perú que entró en funciones en el 2012. A la fecha se han realizado 13 cumbres ministeriales, mecanismo de trabajo contemplado en el acuerdo, que han hecho posible una mayor coordinación y revisión de asuntos para mejorar los alcances del tratado internacional.

Lo reportes más recientes, indican que el $96 \%$ de los bienes y servicios intercambiados entre los socios ya lo hace libre de arancel, concentra el 36\% del PIB de América y el 
Caribe, 57\% de su comercio y capta el 38\% de la inversión extranjera directa. Además, hay negociaciones para que Australia, Canadá, Nueva Zelanda y Singapur se sumen al acuerdo bajo el mecanismo de Estados Asociados, lo que eleva el potencial del tratado. Los reportes oficiales también dan cuenta que se están promoviendo acciones de coordinación con los países del Mercosur (Argentina, Brasil, Paraguay y Uruguay) lo que hace más atractivo este mecanismo comercial ante los ojos del mundo.

No obstante, con respecto a los beneficios contemplados en este acuerdo tanto en materia arancelaria como no arancelaria, inversiones, infraestructura, emprendimiento, movilidad de personas, intercambio académico, turismo, etc., la hipótesis de su escaso aprovechamiento fue comprobada positivamente.

Mediante los dos niveles en que fue desarrollada la presente investigación se encontró evidencia, primero con el caso de estudio, que la AP contempla ventajas que pueden ser aprovechadas por las pequeñas $\mathrm{y}$ medianas empresas siempre y cuando decidan emprender un proceso de internacionalización. Ejemplo de ello es Jova Graneros, quien a partir de la identificación de esas ventajas pudo incrementar sus exportaciones a los países miembros de la AP.

El proceso de internacionalización, como lo señalan las teorías revisadas, implica recursos, un compromiso con el mercado internacional, es gradual, su experiencia es incremental y se compone de varias etapas que conducen a la compañía paulatinamente a los mercados externos, para lo cual necesita identificar sus ventajas competitivas y su capacidad de internalizarlas.
El segundo nivel de la investigación, la encuesta al sector exportador validó que existe un bajo aprovechamiento de las ventajas que contempla la $\mathrm{AP}$ por parte de las empresas exportadoras de Sinaloa, dado su desconocimiento del acuerdo y su alta concentración en el mercado de Estados Unidos. Lo anterior, denota una falta de promoción de dichas ventajas por parte de las autoridades federales y locales responsables de promover el comercio exterior y de apoyar la internacionalización de las empresas, sobre toda de las pequeñas y medianas. Del total de empresas exportadoras entrevistadas, solo el 9.5\% dijo conocer la AP; además, el total de ese porcentaje confesó conocerlo "muy poco" y por iniciativa propia. De igual forma, los entrevistados no recordaron esfuerzos de promoción específicos sobre este acuerdo comercial, ni visitas a sus empresas con el objetivo de promover este tratado internacional.

\section{REFERENCIAS}

Agarwal, S., y Ramaswami, S. (1992). Choice of foreign market entry mode: impact of ownership, location and internalization factors. Journal of International Business Studies, 1-27.

AP (Alianza del Pacífico) (2011). ¿Qué es la alianza del pacífico? Recuperado el 28 de enero de 2017 del sitio web: https://alianzapacifico.net/que-es-la-alianza/

Araya Leandro, A. (2009). El proceso de internacionalización de empresas. TEC Empresarial, Vol. 3, 18-25.

Armario, J., Ruiz, D., y Armario, E. (2008). Market Orientation and Internationalization in Small and Medium-Sized Enterprises. Journal of Small Business Management, 46(4), 485-511.

Balassa, B. (1964). Teoría de la Integración Económica. México: UTEHA.

Balassa, B. (2011). The Theory of Economic Integration (recuperado http://samples.sainsburysebooks.co.uk/9781136646317_sa mple_504906.pdf ed.). New York, USA: Routledge Revivals.

Bárcenas, Alicia (23 de julio de 2018). CEPAL reitera compromiso de apoyo a la Alianza del Pacífico y aplaude 
esfuerzos de convergencia con el Mercosur. Comunicado de prensa (on line), disponible en: https://www.cepal.org/es/comunicados/cepal-reiteracompromiso-apoyo-la-alianza-pacifico-aplaudeesfuerzos-convergencia.

Canals, J. (1994). La internacionalización de la empresa. Cómo evaluar la penetración en mercados exteriores. (1ra. Edición). McGraw-Hill, Madrid, España.

Casillas Bueno, J. (1998). El nivel de internacionalización de las empresas españolas con filiales en el exterior. Investigaciones Europeas de Dirección y Economía de la Empresa. Vol. 4, No. 2, 91-108.

Castellanos, T. (30 de marzo de 2017). ¿Cómo puede aprovechar México sus otros TLC's en el mundo? (D. Ordaz, Entrevistador).

CEPAL (2014). Integración Regional: Hacia una estrategia de cadenas de valor inclusivas. Santiago de Chile: CEPAL.

Cuervo-Cazurra, A. (2004). Dificultades en la internacionalización de la empresa. Universia Business Review (4), 18-29.

Czinkota, M. R., Ronkainen, I. A., y Moffett, M. H. (2005). Negocios Internacionales. México: Cengage Learning.

De La Mora, L. M. (Julio de 2017). El comercio exterior como palanca del crecimiento económico y desarrollo de México. Comercio Exterior Bancomext (11).

Fong, R. C. (2017). Las teorías de la ventaja competitiva. En Carlos Fong (ed.), competitividad e internacionalización de la Pyme en México, análisis sectorial y empresarial. Universidad de Guadalajara, Centro Universitario de Ciencias Económicas Administrativas. ISBN: 978-607742-789-6, pp. 415.

Gómez, A. (14 de mayo de 2013). ¿De qué le sirve a México ser el país con más libre comercio del mundo? (A. Nájar, entrevistador).

Johanson, J., y Vahlne, J.-E. (1977). The Internationalization Process of the Firm: A Model of Knowledge Development and Increasing Foreign Market Commitments. Journal of International Business Studies, Vol. 8, No. 1, pp. 23-32.

Johanson, J., y Vahlne, J.-E. (1990). The Mechanism of Internationalization. International Marketing Review, Vol. 7 (4), pp. 11-24.

Johanson, J., y Wiedersheim-Paul, F. (1975). The Internationalization of the Firm: Four Swedish Cases. The Journal of Management Studies, pp. 305-322.

Kim, H.-S. L. (2009). Marketing Internacional: Teoría y 50 casos. México, DF: Cengage Learning.

Kirchner, A. L. (2000). Comercio Internacional: Metodología para la Formulación de Estudios de Competitividad Empresarial. México, DF.: ECAFSA.
Lam, L. W., y White, L. P. (1999). An Adaptive Choice Model of the Internationalization Process. The International Journal of Organizational Analysis, 7(2), 105-134.

Melin, L. (1992). Internationalization as a strategy process. Strategic Management Journal, 13, 99-118.

Muriel de los Reyes, M. J. (2003). El proceso de internacionalización del sistema bancario español: incidencia de las nuevas tecnologías de la información. Tesis doctoral, facultad de ciencias económicas y empresariales, Universidad de Cádiz, España.

Ocampo, L.E. (2017). Internacionalización y ventaja competitiva de las Pymes. En Carlos Fong (ed.), Competitividad e internacionalización de la Pyme en México, análisis sectorial y empresarial. Universidad de Guadalajara, Centro Universitario de Ciencias Económicas Administrativas. ISBN: 978-607-742-789-6, pp. 415.

Ocampo, L.E.; Alarcón, M.A.; Fong, C. (2014). Determinants of the internationalization of the firm: the accelerated model vs the sequential model. The International Journal of Business and Finance Research, 8(5), pp. 88-93.

OECD. (2009). Top Barriers and Drivers to SME Internationalization. Paris: Report by the OECD Working Party on SMEs and Entrepreneurship.

Peña Nieto, E. (2018). Cumbre en Puerto Vallarta. La Alianza del Pacífico, siete años de integración. El universal (sección opinión), 23 de Julio de 2018.

Psyma Group AG (2017). ¿Cómo determinar el tamaño de una muestra? (Simeon Pickers, Psyme Latina). En línea: http://www.psyma.com/company/news/message/comodeterminar-el-tamano-de-una-muestra (consultado: 10 de agosto de 2017).

Rave, G. E.D. (2010). La internacionalización de las empresas. Lupa Empresarial, Ed. 11, recuperado de http://www.ceipa.edu.co/lupa/index.php/lupa/article/vie w/106/206.

Reyes, M. C. (2008). Formas de Integración Económica: Globalización y Regionalización. México: Limusa.

Rueda, J. F. (2008). Los procesos de internacionalización de la empresa: causas y estrategias que lo promueven. Cuadernos Latinoamericanos de Administración. Vol. IV No. 7., 51-57.

Scientific Software Development GmbH (2017). Atlas.ti, Qualitative Date Analysis.

Villarreal, L. O. (2008). La internacionalización de la empresa: el modelo de las diez estrategias. Revista Internacional Administración y Finanzas. Vol. 1, No. 1, 67-82. 